Trauma Surgery \& Acute Care Open

\title{
Diversity, equity and inclusion in acute care surgery: a multifaceted approach
}

\author{
Bethany L Strong
}

Surgery, University of Maryland Medical Center, Baltimore, Maryland, USA

\section{Correspondence to} Dr Bethany L Strong; bethany. strong@umm.edu

Received 24 November 2020 Accepted 2 February 2021

\section{Linked}

- http://dx.doi.org/10.1136/ tsaco-2020-000646

http://dx.doi.org/10.1136/ tsaco-2020-000644

- http://dx.doi.org/10.1136/

tsaco-2020-000650

- http://dx.doi.org/10.1136/ tsaco-2021-000700

(c) Author(s) (or their employer(s)) 2021. Re-use permitted under CC BY-NC. No commercial re-use. See rights and permissions. Published by BMJ.

To cite: Strong BL. Trauma Surg Acute Care Open 2021:6:e000647.

\section{DIVERSITY IN THE SURGICAL WORKFORCE}

Racial and gender-based diversity in medical student applicants, matriculants and graduates has increased over time. ${ }^{1}$ Underrepresented minority groups, however, continue on the basis of race in medical schools and especially in general surgery residency training programs which lag behind other clinical fields. ${ }^{2}$ Efforts to increase matriculant diversity require an understanding of the interests, perceptions and experiences of those in minority groups much earlier in the process. The conversation of addressing the underrepresented minority applicant pool cannot be had without facing the systemic racism within our educational system that disproportionately disadvantages minority groups. From public school funding and resources to college preparation, students' educational experiences vary widely based on race. ${ }^{3}$ Supplemental pipeline programs exist throughout the country focused on underrepresented minorities to provide science education, career exposure and mentoring. While these programs cannot completely overcome the inequities, there are limited data that shows success in professional development and applying to surgical subspecialities. ${ }^{45}$ Creating a primer for acute care surgery-specific pipeline programs for a variety of educational levels to be implemented locally could be beneficial in increasing diversity in surgical workforce.

General surgery residency without question is a tough road with overall attrition at approximately $18 \%$ nationwide. ${ }^{67}$ Concerningly, a higher ethnicity-based attrition rate has been shown among Hispanic compared with non-Hispanic residents. ${ }^{7}$ In a survey of general surgery residents, Black, Asian and Other residents were less likely to feel they "fit in" at their programs compared with White residents. ${ }^{8}$ Black and Asian residents were more likely to report that attendings would think worse of them if they asked for help with Black residents also being less likely to feel they could count on their even peers for assistance. ${ }^{8}$ Current diversity of program residents correlates with underrepresented minority faculty highlighting that minority residents are choosing programs with representative role models. ${ }^{9}$ Even beyond accepting a diverse class of general surgery residents with the hopes of those residents completing acute care surgery fellowships, cultivating an environment of trust and support is critical to matriculation though all phases of training.

\section{EQUITY IN PATIENT CARE}

Our perceptions of people are created by sociocultural influences that can develop into unconscious implicit biases. Health disparities based on race and ethnicity have been shown to exist for many years and are, in part, attributable to bias and structural violence. ${ }^{10}$ Studies of healthcare professionals as early in their careers as medical students, identified that $69 \%$ had implicit bias in favor of the White people over other races. ${ }^{11}$ Similarly, a previous survey of acute care surgeons showed that $74 \%$ demonstrated an unconscious preference toward White people. ${ }^{12}$ Although direct effects on clinical outcomes have been difficult to show, implicit bias does negatively affect the overall patient care environment. ${ }^{13}$ Interestingly, increased racial diversity of acute care surgeons in addition to other healthcare staff has been shown to mitigate the existence of implicit bias with lower levels of racial bias on webbased testing. ${ }^{14}$ Acute care surgeons treat a diverse and often disadvantaged patient population; therefore, addressing such bias through staff implicit bias training is necessary to be a true patient advocate.

The most pervasive healthcare disparities as it relates to acute care surgery are interpersonal violence and trauma recidivism with homicide being the leading cause of death for non-Hispanic Black men aged 1 to 44 years. ${ }^{15}$ Risk factors for trauma recidivism which lead to a higher risk of death from both injury and non-injury causes include male sex, Black race and a penetrating mechanism of injury. ${ }^{16}$ Hospital-based violence intervention programs encompass the participants with broad social services and often mental health resources with culturally aware case managers from the time of injury. These programs have been shown to be effective with proper implementation including measures to minimize loss to follow-up. In a systematic review, those programs with adequate sample size and a minimum of 6 months of follow-up consistently showed a reduction in injury recidivism and improved conflict resolution. ${ }^{17} \mathrm{~A}$ comprehensive primer is available for institutions to create and implement programs highlighting options to maintain funding. ${ }^{18}$ These programs are critical in full patient recovery and should be routine in trauma centers as meeting the outreach requirement within trauma center verification.

\section{INCLUSION IN SURGICAL LEADERSHIP}

Underrepresented racial minority groups persist within academic surgery and are therefore present in acute care surgical leadership. In a longitudinal study from 2000 to 2015, it was determined that the proportion of Black assistant professors remained stagnant and the proportions of Black associate and full professors decreased to $2.5 \%$ and 
$3.1 \%$, respectively. ${ }^{2}$ An assessment of the Association of Medical Colleges Faculty Roster showed that Black assistant professors had lower 10-year promotion rates across all specialties when compared with Whites. In addition, retention rates were higher for White assistant professors than all racial minority faculty groups leaving us to question why. ${ }^{19}$ While minority surgeons addressing microaggressions and bias from patients is being discussed more openly in recent years, the subjective components of the promotion process also allow for potential bias necessitating transparency. Promoting minorities within acute care surgery programs is crucial to a comprehensive patient care environment and the recruitment of traditionally underrepresented racial groups.?

Unfortunately, there is no simple solution to address diversity, equity and inclusion specific to acute care surgery. The disparities that we see in overall surgical workforce, trauma patient care and acute care surgical leadership are merely a ramification of the systemic racism ingrained within the fabric of this country. There are methods to start to unravel it, but the process involves skills and approaches far removed from the operating room where we are most adept. The initial step is to identify our intrinsic implicit biases that limit us then to address the systems issues through both local and national approaches of program implementation and advocacy efforts. The American Association for the Surgery of Trauma has a broad influence to develop the necessary multifaceted approach not with placating statements or symbolic gestures but through actual change.

Acknowledgements I would like to acknowledge Dr. Rosemary Kozar for encouraging me to submit an essay.

Contributors This essay was conceptualized, drafted in its entirety and finalized by BLS.

Funding The authors have not declared a specific grant for this research from any funding agency in the public, commercial or not-for-profit sectors.

Competing interests None declared.

Patient consent for publication Not required.

Provenance and peer review Commissioned; internally peer reviewed.

Open access This is an open access article distributed in accordance with the Creative Commons Attribution Non Commercial (CC BY-NC 4.0) license, which permits others to distribute, remix, adapt, build upon this work non-commercially, and license their derivative works on different terms, provided the original work is properly cited, appropriate credit is given, any changes made indicated, and the use is non-commercial. See: http://creativecommons.org/licenses/by-nc/4.0/.

\section{REFERENCES}

1 Association of American Medical Colleges2019Diversity in Medicine: Facts and Figures35
2 Abelson JS, Symer MM, Yeo HL, Butler PD, Dolan PT, Moo TA, Watkins AC. Surgical time out: our counts are still short on racial diversity in academic surgery. Am J Surg 2018;215:542-8.

3 Weir K. Inequality at school: what's behind the racial disparity in our education system? American Psychological Association 2016:42 https://www.apa.org/monitor/ 2016/11/cover-inequality-school.

4 Kana LA, Noronha C, Diamond S, Pun M, Broderick MT, Finks J, Sandhu G. Experiential-learning opportunities enhance engagement in pipeline program: a qualitative study of the doctors of tomorrow summer internship program. J Natl Med Assoc 2020;112:15-23.

5 Mason BS, Ross W, Ortega G, Chambers MC, Parks ML. Can a strategic pipeline initiative increase the number of women and underrepresented minorities in orthopaedic surgery? Clin Orthop Relat Res 2016;474:1979-85.

6 Khoushhal Z, Hussain MA, Greco E, Mamdani M, Verma S, Rotstein O, Tricco AC, AlOmran M. Prevalence and causes of attrition among surgical residents: a systematic review and meta-analysis. JAMA Surg 2017;152:265-72.

7 Gifford E, Galante J, Kaji AH, Nguyen V, Nelson MT, Sidwell RA, Hartranft T, Jarman $B$, Melcher $M$, Reeves $M$, et al. Factors associated with general surgery residents' desire to leave residency programs: a multi-institutional study. JAMA Surg 2014;149:948-53.

8 Wong RL, Sullivan MC, Yeo HL, Roman SA, Bell RH, Sosa JA. Race and surgical residency: results from a national survey of 4339 us general surgery residents. Ann Surg 2013;257:782-7.

9 Jarman BT, Borgert AJ, Kallies KJ, Joshi ART, Smink DS, Sarosi GA, Chang L, Green $J M$, Greenberg JA, Melcher ML, et al. Underrepresented minorities in general surgery residency: analysis of Interviewed applicants, residents, and core teaching faculty. J Am Coll Surg 2020;231:54-8.

10 Institute of Medicine (US) Committee on Understanding and Eliminating Racial and Ethnic Disparities in Health Care. Unequal treatment: confronting racial and ethnic disparities in health care. Washington, DC: National Academies Press, 2003.

11 Haider AH, Sexton J, Sriram N, Cooper LA, Efron DT, Swoboda S, Villegas CV, Haut ER, Bonds M, Pronovost PJ, et al. Association of unconscious race and social class bias with vignette-based clinical assessments by medical students. JAMA 2011;306:942-51.

12 Haider AH, Schneider EB, Sriram N, Dossick DS, Scott VK, Swoboda SM, Losonczy L, Haut ER, Efron DT, Pronovost PJ, et al. Unconscious race and class bias: its association with decision making by trauma and acute care surgeons. J Trauma Acute Care Surg 2014;77:409-16

13 Blair IV, Steiner JF, Fairclough DL, Hanratty R, Price DW, Hirsh HK, Wright LA, Bronsert M, Karimkhani E, Magid DJ, et al. Clinicians' implicit ethnic/racial bias and perceptions of care among black and Latino patients. Ann Fam Med 2013;11:43-52.

14 Zebib L, Strong B, Moore G, Ruiz G, Rattan R, Zakrison TL. Association of racial and socioeconomic diversity with implicit bias in acute care surgery. JAMA Surg 2019;154:459-61.

15 Sumner SA, Mercy JA, Dahlberg LL, Hillis SD, Klevens J, Houry D. Violence in the United States: status, challenges, and opportunities. JAMA 2015:314:478-88.

16 Strong BL, Greene CR, Smith GS. Trauma recidivism predicts long-term mortality: missed opportunities for prevention (retrospective cohort study). Ann Surg 2017;265:847-53.

17 Strong BL, Shipper AG, Downton KD, Lane WG. The effects of health care-based violence intervention programs on injury recidivism and costs: a systematic review. $J$ Trauma Acute Care Surg 2016;81:961-70.

18 Dicker R, Gaines B, Bonne S, et al. Violence intervention programs: a primer for developing a comprehensive program for trauma centers. Bull Am Coll Surg 2017 https://www.facs.org/quality-programs/trauma/advocacy/ipc/firearm-injury/hvipprimer.

19 Abelson JS, Wong NZ, Symer M, Eckenrode G, Watkins A, Yeo HL. Racial and ethnic disparities in promotion and retention of academic surgeons. Am J Surg 2018:216:678-82. 